\title{
LA CARTA SOCIAL EUROPEA DEL CONSEJO DE EUROPA Y SU ÓRGANO DE CONTROL: EL COMITÉ EUROPEO DE DERECHOS SOCIALES
}

JEAN-MICHEL BELORGEY 
I. CONSIDERACIONES INTRODUCTORIAS: APROXIMACIÓN A LA CARTA SOCIAL EUROPEA. II. CARACTERIZACIÓN Y ALCANCE DE LOS PODERES DEL COMITÉ EUROPEO DE DERECHOS SOCIALES. III. CONTRIBUCIÓN DEL COMITÉ EUROPEO AL PROGRESO DE LOS DERECHOS SOCIALES. IV. LA TAREA ESPECÍFICA DEL COMITÉ EUROPEO EN ÁMBITOS SOCIALES IMPORTANTES: 1. EI empleo. 2. La protección social. 3. La pobreza y la precariedad. V. REFLEXIONES FINALES. 


\title{
LA CARTA SOCIAL EUROPEA DEL CONSEJO DE EUROPA Y SU ÓRGANO DE CONTROL: EL COMITÉ EUROPEO DE DERECHOS SOCIALES*
}

POR

\author{
JEAN-MICHEL BELORGEY
}

Antiguo presidente (2003-2006) y ponente general del Comité Europeo de Derechos Sociales. Presidente de la Sección de Informes y Estudios del Consejo de Estado francés

\section{CONSIDERACIONES INTRODUCTORIAS: APROXIMACIÓN A LA CARTA SOCIAL EUROPEA}

La Carta Social del Consejo de Europa ${ }^{1}$ constituye, sin lugar a dudas, el instrumento internacional que contiene el más completo catálogo de derechos sociales —en sentido amplio-. La Carta original, fir-

* El presente trabajo debe aparecer publicado asimismo en 2007 en versión original francesa (bajo el título "La Charte sociale du Conseil de l'Europe et son organe de régulation: le Comité européen des droits sociaux") en Revue de Droit Sanitaire et Sociale. Traducción del original francés por Luis Jimena Quesada (Universitat de València, España).

1 No se abordará en el presente trabajo, de modo expreso, salvo para efectuar una caracterización de sus grandes líneas, ni el contenido de la Carta, ni las reglas que presiden el modo de proceder al examen de los informes gubernamentales. A este respecto, existen obras y publicaciones insuficientemente conocidas, pero de 
mada en 1961 y entrada en vigor el 26 de febrero de 1965, se componía de un preámbulo, 19 puntos (parte I) y 38 artículos agrupados en cuatro partes (II a V) -únicamente la parte II, esto es los artículos 1 a 19, se refería a los derechos garantizados-, así como de un anexo. La Carta revisada, firmada en Estrasburgo el 3 de mayo de 1996, entró en vigor en 1999; se compone igualmente de un preámbulo, 31 puntos (parte I) y 48 artículos (31 artículos numerados del 1 al 31, y 14 numerados de la $\mathrm{A}$ a la 0 ) que constituyen sus partes II a $\mathrm{V}$, así como — nuevamente- de un anexo que precisa el alcance de los diversos artículos. Las principales innovaciones introducidas por la Carta revisada se refieren:

- Al derecho a la igualdad de oportunidades y de trato en materia de empleo y de profesión, sin discriminación por razón del sexo (nuevo artículo 20), y al derecho de los trabajadores que tengan responsabilidades familiares a una igualdad de trato (nuevo artículo 27);

- A diversos derechos que atañen a las relaciones laborales, como son el derecho a la información y a la consulta (nuevo artículo 21); el derecho a participar en la determinación y en la mejora de las condiciones de trabajo (nuevo artículo 22); el derecho a la protección en caso de despido (nuevo artículo 24); el derecho a la protección de los haberes en caso de insolvencia del empleador (nuevo artículo 25); el derecho a la dignidad en el trabajo (nuevo artículo 26); el derecho de los representantes de los trabajadores a una protección y a facilidades en la empresa (nuevo artículo 28); y el derecho a la información y consulta en los procedimientos de despido colectivo (nuevo artículo 29);

calidad: La Charte sociale européenne, bajo la dirección de J. F. AKANDJI-KomBÉ y S. LECLERC, Bruylant, Bruxelles, 2001; AKANDJI-KomBÉ, J. F.: "L'application de la Charte sociale européenne: la mise en oeuvre de la procédure de réclamations collectives", Droit social 9/10, septiembre-octubre 2000; KONSTANTINOU, A.: "L'interprétation de la Charte sociale européenne dans le cadre des réclamations collectives", bajo la dirección de I. KITSOU-MILONAS, Université Robert Schuman, Institut des Hautes Études Européennes, Strasbourg, 2006; además, se encuentra en prensa sobre este mismo tema la obra del Profesor Akandji-Kombé; por añadidura, resulta de gran utilidad la lectura de las crónicas (en la Revue trimestrielle des Droits de l'Homme, octubre de 2001, n. ${ }^{\circ} 48$; enero de 2003, n. ${ }^{\circ} 53$; enero de 2004, n. ${ }^{\circ} 5$; julio de 2005, n. ${ }^{\circ} 63$ ) redactadas por este mismo profesor sobre las decisiones del Comité Europeo de Derechos Sociales sobre las reclamaciones colectivas. Por tanto, el análisis que se propone en el presente trabajo pretende deliberadamente abordar el meollo de los interrogantes que se plantea el Comité respecto al alcance de su mandato y, más ampliamente, de la Carta Social del Consejo de Europa. 
- El derecho a la protección contra la pobreza y la exclusión social (nuevo artículo 30);

- El derecho a la vivienda (nuevo artículo 31).

La mayor parte de los nuevos derechos acabados de mencionar constituyen el desarrollo de los que figuran en los artículos de la Carta original y respecto de los cuales, a menudo, el Comité Europeo de Derechos Sociales ya había extraído consecuencias próximas a las que se han recogido en los nuevos artículos introducidos en la Carta revisada.

El mecanismo de adhesión a la Carta Social es un mecanismo de una gran originalidad, respecto del cual debe reconocerse su flexibilidad sin, por ello, desconocer algunos inconvenientes (a saber, la tentación para algunos Estados de intentar salvar sus puntos deficitarios a través de la aceptación de sólo aquellos artículos que no les comprometen a demasiados esfuerzos). Se trata de una ratificación "a la carta", con la excepción de aquellos artículos que los Estados deben suscribir necesariamente, y que se acostumbra a designar bajo el nombre de "núcleo duro". Para la Carta revisada, los Estados deben aceptar al menos 6 de los 9 artículos siguientes: 1 (derecho al trabajo), 5 (derecho de sindicación), 6 (derecho a la negociación colectiva), 7 (derecho de los niños y los adolescentes a protección), 12 (derecho a la seguridad social), 13 (derecho a la asistencia social y médica), 16 (derecho de la familia a la protección), 19 (derecho de los trabajadores migrantes y sus familias a protección y asistencia), 20 (derecho a la igualdad de oportunidades y de trato en materia de empleo sin discriminación por razón de sexo). Sin embargo, conviene subrayar que dichas disposiciones, que vienen a retomar, con algunas adiciones, las disposiciones del "núcleo duro" de la Carta original de 1961, no representan necesariamente las disposiciones más importantes; en particular, cabe lamentar que el artículo 4.1 (derecho a una remuneración equitativa), así como los artículos 30 (derecho a la protección contra la pobreza y la exclusión social) y 31 (derecho a la vivienda), no figuren en ese "núcleo duro".

Los 47 Estados miembros del Consejo de Europa han firmado la Carta, ya sea la original, ya sea la Carta revisada (41 han firmado la Carta revisada); 39 Estados han ratificado una u otra Carta (23 la Carta revisada) según, teniendo en cuenta el mecanismo de ratificación anteriormente descrito, un número variable de artículos².

2 Para ver el estado de ratificaciones y las disposiciones aceptadas por cada Estado, puede acudirse al sitio web del Consejo de Europa (www.coe.int), accediendo a la Carta Social Europea a través del enlace relativo a derechos humanos. 
La Carta Social del Consejo de Europa constituye, en el terreno de los derechos humanos, la prolongación del Convenio Europeo para la salvaguardia de los derechos humanos y las libertades fundamentales. Algunos de sus artículos, de hecho, se hacen eco de enunciados que son muy próximos a los que figuran en el Convenio. Es el caso, en especial, del artículo E, el cual prescribe que "el disfrute de los derechos reconocidos en la... Carta [debe ser asegurado] sin discriminación alguna basada, en particular, en la raza, el color, el sexo, la lengua, la religión, las opiniones políticas o de otra naturaleza, la extracción u origen social, la salud, la pertenencia a una minoría nacional, el nacimiento o cualquier otra situación", prohibiendo en consecuencia cualquier discriminación; este artículo es, salvo con algunos matices, idéntico al artículo 14 del Convenio. Otros artículos de la Carta tienen, cuando menos, el mismo objeto que algunos artículos del Convenio. Es el caso particular del artículo 5 referente al derecho de sindicación, así como, aunque de manera menos obvia, de algunos otros.

Entre los dos instrumentos existe no obstante una diferencia esencial: la que tiene que ver con sus respectivos ámbitos subjetivos de aplicación; el Convenio Europeo de Derechos Humanos se aplica a "toda persona" que se encuentre bajo la jurisdicción de los Estados Partes (artículo 1 del Convenio); la Carta únicamente se aplica, al menos en principio, a los nacionales de los Estados Partes y, más aún, a los nacionales de los Estados Partes que se encuentren en situación de estancia o de trabajo regular (anexo a la Carta). A esta diferencia no cabría, sin embargo, atribuirle un alcance absolutamente general, pues mal puede entenderse cómo el beneficio de determinados artículos relativos a algunos derechos que tienen relación directa con el derecho a la vida y a la dignidad estaría reservado no sólo a los nacionales de los Estados Partes en situación regular, sino que además se negaría a los nacionales de los otros Estados con independencia de cuál fuere su situación de estancia. A este respecto, de hecho, el Comité Europeo de Derechos Sociales ha entendido lo contrario al pronunciarse con ocasión del examen de la reclamación colectiva $n .^{\circ}$ 14/2003 (FIDH contra Francia) relativa al derecho a la protección social en materia de beneficios sanitarios de los menores extranjeros ${ }^{3}$.

${ }^{3}$ Reclamación n. ${ }^{\circ}$ 14/2003 (Federación internacional de ligas de derechos humanos contra Francia, decisión de fondo de 8 de septiembre de 2004). 


\section{CARACTERIZACIÓN Y ALCANCE DE LOS PODERES DEL COMITÉ EUROPEO DE DERECHOS SOCIALES}

Los poderes del Comité Europeo de Derechos Sociales, órgano de control de la Carta Social del Consejo de Europa, actualmente compuesto por 15 miembros ${ }^{4}$, que se limitaban en su origen al examen de los informes periódicamente presentados por los Estados con objeto de dar cuenta de la ejecución de sus obligaciones asumidas a tenor de la Carta, se vieron sensiblemente reforzados con motivo de la adopción, en 1995, de un Protocolo adicional a la Carta original (dicho protocolo entró en vigor en 1998), cuyas disposiciones quedaron integradas en el artículo D (parte II) de la Carta revisada. Desde entonces, y a condición de que cada Estado afectado haya aceptado su jurisdicción, tiene vocación y competencia para pronunciarse sobre reclamaciones colectivas que emanen de organizaciones sindicales nacionales o internacionales, o también de organizaciones que ostenten estatuto "participativo" ante el Consejo de Europa y se encuentren inscritas en la lista establecida por el Comité gubernamental de la Carta Social. Todos los Estados Partes en la Carta no han aceptado su jurisdicción. Únicamente catorce lo han hecho. $Y$ uno solamente, Finlandia, ha aceptado igualmente que puedan ser presentadas reclamaciones colectivas no sólo por las organizaciones acabadas de enumerar, sino asimismo por cualquier organización no gubernamental nacional. La jurisdicción del Comité Europeo de Derechos Sociales no es una jurisdicción en toda su plenitud; sus decisiones no son directamente ejecutivas. Sin embargo, el Comité de Ministros, en todos los casos -excepto en uno en el que entendió afectado el alcance de sus poderes ${ }^{5}$ - les ha dado semejante

4 Lamentablemente designados todavía, como en su origen, por el Comité de Ministros, y ello en detrimento de las disposiciones del artículo C de la Parte IV de la Carta revisada, que prevé la elección por la Asamblea parlamentaria. Dichos miembros tampoco son llamados a pronunciar, en el momento de su toma de posesión, una declaración solemne mediante la que se comprometan a actuar con absoluta independencia.

5 Dicho caso es el de la Reclamación n. ${ }^{\circ}$ 9/2000 (Confederación francesa de directivos-Confederación general de ejecutivos contra Francia, decisión de fondo de 16 de noviembre de 2001). El Comité de Ministros, en su Resolución ResChS(2002)4 de 29 de marzo de 2002 pareció rechazar la decisión del Comité Europeo de Derechos Sociales. Sin embargo, la misma reclamante presentó una segunda reclamación [Reclamación n. ${ }^{\circ}$ 16/2003 (Confederación francesa de directivos-Confederación general de ejecutivos contra Francia, decisión de fondo de 12 de octubre de 2004)], con motivo de la cual el Comité Europeo de Derechos Sociales confirmó su decisión precedente, de la que el Comité de Ministros tomó buena nota [Resolución ResChS(2005)7 de 4 de mayo de 2005]. 
fuerza. Al contrario, por ende, nos encontramos no tanto ante una justicia delegada, sino ante una justicia retenida. Ello no obstante, no debe olvidarse que esa era la misma condición que ostentaba, hasta finales del segundo tercio del siglo XIX, el Consejo de Estado francés. La actividad de examen de reclamaciones colectivas por el Comité Europeo de Derechos Sociales evidentemente presenta, más allá del ámbito extremadamente vasto de cuestiones sobre las que pueden versar las reclamaciones por el hecho de la amplitud de los temas tratados por la Carta, cuatro virtudes.

En primer lugar, se trata de una actividad jurisdiccional, o cuasi jurisdiccional, en un ámbito, el de los derechos sociales, en el que intervienen muy poco, y en todo caso de manera muy insuficiente, las jurisdicciones internacionales, incluso las europeas. El Tribunal de Justicia de las Comunidades Europeas y el Tribunal Europeo de Derechos Humanos se decantan por efectuar incursiones limitadas. En parte por ausencia de bases jurídicas habilitantes... En parte por propensión a la autocensura. Por lo demás, en lo que concierne al Tribunal de Justicia de la Unión Europea, ello se debe al hecho de la parsimonia con la que las jurisdicciones nacionales tienden a hacer uso de las cuestiones prejudiciales, las cuales naturalmente sólo pueden versar sobre problemas respecto de los cuales los Tribunales destinatarios están habilitados para pronunciarse.

En segundo lugar, el Comité Europeo de Derechos Sociales es una jurisdicción que se mueve desde los principios hacia los derechos, hacia los derechos consignados en los ordenamientos positivos nacionales, e incluso hacia derechos concretos, puesto que los exámenes de situación efectuados por el Comité no tratan sólo sobre los textos constitucionales, legislativos o reglamentarios vigentes en los Estados concernidos, sino también sobre las prácticas. Esto es original (y precioso para el progreso de los derechos sociales), máxime ante la reticencia manifestada por numerosos órganos jurisdiccionales nacionales a la hora de reconocer efectos directos a los instrumentos internacionales suscritos por los Estados; máxime asimismo ante las extrañas disposiciones introducidas en la Parte II del Proyecto de Constitución Europea que retomaba la Carta de los Derechos Fundamentales de la Unión Europea (artículo II-112.5 en la numeración del proyecto de Tratado constitucional), con objeto de prohibir a cualquier juez el basarse en los enunciados de la Carta con otra finalidad que no sea la de la apreciación de la legalidad de los derechos positivos, comunitarios o nacionales (dicho de otro modo, en ausencia de un derecho positivo, los principios carecen de alcance, o cuando menos pueden ser ignorados por los Estados, en detrimento de los 
compromisos que éstos han suscrito - para mayor gloria de ellos-, sin sanción alguna6 ${ }^{6}$.

La tercera virtud del procedimiento de examen de las reclamaciones colectivas por el Comité Europeo de Derechos Sociales reside en la simplicidad de dicho procedimiento, y en su eficacia. No es necesario antes de interponer estas reclamaciones, y ello constituye una diferencia considerable con respecto a las demandas que se formulan ante el Tribunal Europeo de Derechos Humanos, el haber hecho valer previamente otras vías de recurso. Ciertamente, hace falta, al tratarse de reclamaciones colectivas, encontrar una organización dispuesta a entablarlas, lo que no va de suyo, tanto más cuanto que las organizaciones sindicales no poseen en todos los Estados una vocación de interesarse, o al menos de preocuparse, por otros problemas que no sean los atinentes al Derecho laboral, de suerte que un solo país (como se dijo, Finlandia) ha aceptado las reclamaciones colectivas procedentes de organizaciones no gubernamentales nacionales. Pero la experiencia demuestra que sí es posible encontrar organizaciones dispuestas a implicarse, entre ellas precisamente algunas de las que gozan de estatuto consultivo ante el Consejo de Europa y deciden echar una mano a camaradas menos favorecidos. Y, en la medida en que se dirijan contra textos normativos, contra el conjunto de una política, o con-

6 Esto no hace sino agravar las inquietudes que pueden ser alimentadas con respecto al impacto de la Carta de los derechos fundamentales, cuyas disposiciones son en gran medida muy elípticas, o caricaturalmente tautológicas: «toda persona tiene derecho a acceder a...", o "a beneficiarse de..." cuidados médicos, prestaciones de seguridad social, ayuda social «en las condiciones establecidas por la legislación y las prácticas nacionales». Lo cual es no decir nada. Para los artículos redactados de tal modo, las cautelas previstas por el artículo II-112(5) eran por lo demás inútiles... Una fórmula que permitiría superar las confusiones susceptibles de surgir como consecuencia de la coexistencia de las dos cartas que tratan de derechos sociales - la del Consejo de Europa y la de la Unión Europea-, una razonablemente exigente, la otra al menos de "perfil bajo", consistiría en la ratificación por la Unión de la Carta del Consejo de Europa. Es sabido que el Tribunal de Justicia comunitario, en el pasado ya tuvo ocasión de emitir un dictamen en el que concluyó la imposibilidad para la Unión de ratificar el Convenio Europeo de Derechos Humanos, lo que para algunos conduciría asimismo a fortiori a la misma imposibilidad respecto de la Carta Social Europea. Las cosas parecen evolucionar. Pero no es indiferente saber bajo qué signo. A tal efecto, los trabajos del Profesor Olivier DE SCHUITER, por clarificadores que resulten inspirando de tanto en tanto algunas inquietudes, en particular en la medida en que sugieren que la adhesión de la Unión a la Carta Social no significaría que ésta haya de surtir efectos razonablemente vinculantes para las opciones operadas por la Unión, a tenor del principio de autonomía de la Unión Europea. 
tra la ausencia de un texto o de una política, dichas reclamaciones colectivas, de algún modo como sucede en el ámbito nacional con los recursos por abuso de poder contra textos reglamentarios o por inconstitucionalidad contra leyes, pueden desempeñar y desempeñan una función de prevención de futuros litigios individuales. Incluso ha llegado a darse el supuesto (lo que ha ocurrido con motivo de un recurso contra las limitaciones introducidas en Portugal en relación con el ejercicio de las libertades sindicales por parte de los policías) de que el Gobierno denunciado haya procedido a modificar durante su tramitación la regulación del derecho contestado. Las decisiones del Comité Europeo de Derechos Sociales son adoptadas en un plazo que oscila entre 2 a 6 meses en lo atinente a la admisibilidad, y de 6 a 9 meses para el pronunciamiento sobre el fondo (a lo que hay que añadir el plazo necesario para la toma de posición del Comité de Ministros o, en caso de silencio por parte de éste, 4 meses -es mucho, sin duda demasiado).

La cuarta virtud del procedimiento de examen de las reclamaciones colectivas por parte del Comité Europeo de Derechos Sociales tiene que ver con su ya larga experiencia en materia de interpretación de las disposiciones de la Carta insuficientemente claras o ambiguas, interpretación que se ha visto llamado a desarrollar con ocasión del examen de los informes; tiene que ver asimismo con la posibilidad de hacer jugar, de manera concurrente con las disposiciones de la mayor parte de los artículos, las disposiciones transversales del artículo E de la Carta relativas a la discriminación, cuyo estrecho parentesco con las del artículo 14 del Convenio Europeo de Derechos Humanos ya ha sido puesto de manifiesto, pero que, teniendo en cuenta la extensión de los ámbitos cubiertos por la Carta (ostensiblemente mucho más amplios que los cubiertos por el Convenio), pueden tener un impacto mucho mayor que las del artículo 14 del Convenio 7.

7 Lo cual contribuye a explicar los límites con los que se enfrenta la intervención del Tribunal Europeo de Derechos Humanos, límites que desaparecerán desde el momento en que ha entrado en vigor, para los Estados que lo han ratificado, el Protocolo $\mathrm{n}$. $^{0} 12$ al Convenio Europeo, que otorga al Tribunal de Estrasburgo, en materia de discriminación, competencias que exceden de la delimitación de los derechos cubiertos por el Convenio, puesto que se extienden no sólo a las discriminaciones que obstaculicen el disfrute de todo derecho previsto por un texto, sino también las discriminaciones perpetradas por cualquier autoridad pública, cualquiera que sea la naturaleza de dichas discriminaciones. La entrada en vigor del Protocolo n. ${ }^{\circ} 12$, no obstante, no debería privar de alcance a los mecanismos de control específicos previsibles, puesto que éstos se ocupan -en cada uno de los ámbitos en los que operan- no únicamente de las iniciativas que pudieren revestir un carácter discriminatorio, sino asimismo de las abstenciones del mismo alcance, que serán más di- 
El número de decisiones de fondo dictadas hasta el presente por el Comité Europeo de Derechos Sociales sobre reclamaciones colectivas ya ha superado la treintena. Estas reclamaciones han versado sobre cuestiones tan diversas como:

- El derecho a elegir libremente su trabajo (objetores de conciencia griegos);

- El monopolio atribuido a los nacionales en algunas profesiones (guías de museos en Francia);

- El derecho de sindicación (aspectos positivos y negativos), en Portugal y en Suecia;

- La duración del trabajo en Francia (las denominadas leyes "Aubry" y "Fillon»);

- El derecho a la protección social en materia de salud de los menores extranjeros, incluso encontrándose en situación irregular (Francia);

- La política seguida con respecto a los Gitanos (Grecia, Italia, Bulgaria);

- Los castigos corporales infligidos a los niños (Bélgica, Irlanda, Italia, Portugal);

- Las modalidades de adopción de medidas a favor de algunas personas con discapacidad, en particular los autistas (Francia);

- Los riesgos generados, tanto en perjuicio de las personas que viven en los alrededores como de los trabajadores, por la insuficiencia de mecanismos de prevención puestos en práctica en el marco de la explotación del lignito y de centrales eléctricas que utilizan el lignito como combustible (Grecia).

Algunas otras reclamaciones todavía están tramitándose, en particular las formulas por A.T.D. y por FEANSTA con relación a la política de vivienda en Francia, que suscitan cuestiones delicadas que afectan

fíciles de articular en virtud del Protocolo n. ${ }^{\circ}$ 12. Naturalmente, cabe plantear la cuestión de las divergencias de apreciación susceptibles de producirse en los asuntos en que dos instituciones, el Tribunal Europeo y otro órgano especializado de control, fueren igualmente competentes para intervenir, mediante vías y en momentos diferentes. Sobre estas cuestiones, véase "La non discrimination: un droit fundamental", Seminario sobre la entrada en vigor del Protocolo n. ${ }^{\circ} 12,11$ de octubre de 2005, Actes du Conseil de l'Europe, 2006. 
especialmente al alcance del artículo 31 de la Carta (derecho a la vivienda $^{8}$, y al modo en que dicha disposición está en conjunción con los artículos 16 y 30, que se ocupan respectivamente de la protección de la familia y de la lucha contra la pobreza y la exclusión social ${ }^{9}$.

En todos los asuntos juzgados, la fuerza ejecutiva dada por el Comité de Ministros a las decisiones del Comité Europeo de Derechos Sociales ha conducido a los Estados a darles cumplimiento, más o menos exactamente, pero a darles cumplimiento.

\section{CONTRIBUCIÓN DEL COMITÉ EUROPEO DE DERECHOS SOCIALES AL PROGRESO DE LOS DERECHOS SOCIALES}

Ya se trate de la lectura de informes, o del examen de reclamaciones colectivas, la postura del Comité Europeo de Derechos Sociales puede ser definida globalmente en los términos que siguen.

La preocupación del Comité radica en respetar la diversidad de las tradiciones y de los modelos nacionales, así como en tomar en cuenta el desigual grado de prosperidad económica de los diferentes Estados miembros. El hecho es que, en algunos Estados existe una tradición de hacer política que gira en torno a la fabricación de normas, de política centralizada, mientras que en otros existe una tradición de delegación en los interlocutores sociales o en las entidades locales; y esto dota de perfiles muy diferentes a las políticas seguidas por los diferentes Estados Partes. El hecho es, asimismo, que según el país se encuentre en una estado de mayor o menor prosperidad, la cuestión del nivel de las prestaciones otorgadas a título de la seguridad social o de la asistencia social se plantea en término diferentes, e incluso la línea divisoria entre

8 Este artículo dispone en particular que: «Para garantizar el ejercicio efectivo del derecho a la vivienda, las Partes se comprometen a adoptar medidas destinadas: 1. a favorecer el acceso a la vivienda de un nivel suficiente; 2 . a prevenir y paliar la situación de carencia de hogar con vistas a eliminar progresivamente dicha situación; 3. a hacer asequible el precio de las viviendas a las personas que no dispongan de recursos suficientes".

${ }^{9}$ El artículo 30 prevé, por su parte, que: «Para garantizar el ejercicio efectivo del derecho a protección contra la pobreza y la exclusión social, las Partes se comprometen: a) a adoptar medidas en el marco de un planteamiento global y coordinado para promover el acceso efectivo, en particular al empleo, a la vivienda, a la formación, a la enseñanza, a la cultura, y a la asistencia social y médica, de las personas que se encuentren o que corran el riesgo de encontrarse en una situación de exclusión social o de pobreza, así como de sus familias; b) a revisar estas medidas con vistas a su adaptación, si resulta necesario". 
la seguridad social en el sentido del artículo 12 de la Carta y la asistencia social en el sentido del artículo 13 pueden variar considerablemente. Lo que entonces importa hacer prevalecer como norma de referencia es que todos los Estados, cualquiera que sea su tradición nacional, cualquiera que sea su nivel de prosperidad económica, deben manifestar una verdadera sinceridad en la aplicación de los compromisos asumidos. Lo que se debe hacer prevalecer como principio es que, incluso cuando un Estado se encuentre profundamente descentralizado, ya sea desde hace un siglo o más, es el Estado el que se ha comprometido a respetar un cierto número de obligaciones, lo que le impide sostener la tesis según la cual, puesto que los operadores son los interlocutores sociales, son éstos los que hacen lo que quieren o, del mismo modo, puesto que lo son las entidades locales, el Estado no puede ponerlas bajo tutela.

El Estado es, por ende, responsable de los compromisos contraídos en el marco de la Carta: lo cual significa que, cualquiera que sea la organización institucional por la que haya optado, y que el Comité Europeo de Derechos Sociales no va a entrar a contestar, el Estado debe estar en condiciones de asegurar, bien mediante la ley bien a través de la jurisprudencia, que las soluciones adoptadas no comporten violaciones de la Carta. Esto ha sido puesto de manifiesto de manera extremadamente clara a las autoridades suecas, con ocasión de diversos encuentros del Comité Europeo de Derechos Sociales con ellas; éstas han acabado por comprenderlo, incluso aunque ello les haya disuadido igualmente a la hora de aceptar nuevas disposiciones de forma inmediata, de contraer obligaciones en nuevos terrenos. Ello había sido declarado, por lo demás, en la decisión del Comité Europeo de Derechos Sociales referente a Suecia, y ha sido confirmado en las decisiones referentes a los Gitanos en Grecia y en Italia. "Ya saben, no somos nosotros, el problema es de las entidades locales». Tal vez. Pero las entidades locales afectadas son griegas o italianas. Por tanto, es preciso que Grecia o Italia, que han ratificado la Carta, pongan los medios para que las competencias atribuidas a las entidades locales sean ejercidas en condiciones que permitan satisfacer las obligaciones de la Carta. Y la misma regla juega para Suecia en lo que concierne a las competencias que recaen en los interlocutores sociales. Tratándose de niveles desiguales de desarrollo, no pueden exigirse en todos los sitios las mismas prestaciones. Algunas prestaciones, que se encuentran al alcance de países que han conseguido un cierto grado de prosperidad, no están al alcance de otros países. Y, una vez más, hay que respetar las peculiaridades de los Estados miembros. Pero debe conseguirse igualmente que la firma de compromisos en virtud de la Carta 
no conduzca a exigencias injustamente diferentes para los diversos Estados miembros.

La segunda categoría de principios que anima los trabajos del Comité de Derechos Sociales es que éste no se interesa únicamente por los textos. La Carta impone que se adopten normas, ya sea por vía legislativa o reglamentaria, o convencional cuando se ha delegado en los interlocutores sociales, pero también exige que las prácticas sean aceptables. Es decir, si un país adopta textos de muy bella factura —algunos son expertos en este terreno-, pero la práctica es mala, ello es inaceptable. El Comité Europeo de Derechos Sociales hace Derecho; esta es precisamente su originalidad; no se interesa solamente por los buenos usos; considera que es necesario que exista una base jurídica habilitante para los derechos reconocidos y que estos derechos puedan ser movilizados. Ahora bien, más allá del Derecho, quiere que las prácticas sean buenas, y si un texto es excelente pero la práctica es mala, esto también es inaceptable. En una palabra, no es que el Comité se limite a hacer Derecho, en lo que radica una de sus razones de ser, sino que quiere que el Derecho tome cuerpo. Quiere a la vez buenos textos y buenas prácticas. Sobre el asunto muy delicado, y a propósito del cual el Comité se encontró por momentos bastante dividido, de los castigos corporales infligidos a los niños, aquél no adoptó una actitud nominalista. No dijo que había que enunciar esta cuestión palabra por palabra en los textos de Derecho positivo, sino que únicamente se limitó a declarar que en ese terreno debía haber suficientes textos de Derecho positivo para que la actitud de los órganos jurisdiccionales llamados a pronunciarse en tal ámbito quedara bien delimitada, para que la creatividad requerida de esas jurisdicciones al dar cumplimiento a la Carta no apareciera como excesiva o desconectada de la sensibilidad que prevalezca en el sistema jurídico del país considerado. Y esto es lo que ha marcado la diferencia, a fin de cuentas, entre países que contaban con normas muy detalladas, países que no contaban en absoluto con ninguna normativa, y países que sin tener normas muy precisas sí disponían de normas consistentes que ponían de manifiesto una toma de postura constante por parte de sus órganos judiciales, lo cual permitía colegir que esa postura no cedería ante supuestos adversos o con el transcurso del tiempo (el Comité Europeo de Derechos Sociales, que no es infalible, por cierto se equivocó en este ámbito en relación con Portugal, viéndose abocado, algunos meses después de su primera decisión referente a dicho país, a adoptar una decisión de sentido contrario a la vista de una sentencia ostensiblemente chocante de la jurisdicción civil superior portuguesa). Tarea difícil, muy próxima de aquella a la que se dedican otras jurisdicciones internacionales, o algunas jurisdicciones nacionales. 
En el mismo orden de ideas, el Comité Europeo de Derechos Sociales dedica su tiempo a verificar que los derechos sociales enunciados por textos son susceptibles, incluso en situaciones marginales, de ser reclamados ante los jueces. Vela asimismo por que grupos minoritarios, o personas en situación difícil, culturalmente o porque pertenecen a categorías frágiles, no queden descartados o excluidos respecto a los derechos reconocidos y globalmente puestos en práctica. Es por ello que el Comité confiere gran importancia a la manera en que se asegura el acceso a los derechos sociales. El Consejo de Europa ha establecido a este respecto, en el marco de su Comité de Cohesión Social, un informe muy detallado redactado por la pluma de la experta irlandesa Mary Daly. El Comité Europeo de Derechos Sociales se ve impregnado de las mismas preocupaciones que se expresan en dicho informe. Así, presta especial atención a la cuestión de la justiciabilidad, del derecho a un recurso ante jurisdicciones independientes, cuando alguien vea rechazados los derechos que entiende ostentar (y que, por lo demás, a menudo tiene) sin haber conseguido que se les reconozcan. En tal caso, es preciso que exista un juez que presente características de suficiente competencia y de suficiente independencia.

El ejemplo francés es a este respecto ilustrativo. El sistema francés de recurso contra las decisiones de denegación de peticiones de ayuda social (de asistencia social) es un sistema que no se sostiene, que no es conforme a los compromisos suscritos en virtud de la Carta. El Tribunal Europeo de Derechos Humanos ha declarado en diversas ocasiones que las jurisdicciones francesas competentes en materia de ayuda social no cumplían con las obligaciones del artículo 6 del Convenio Europeo de Derechos Humanos. Por su lado, el Comité Europeo de Derechos Sociales también se ha pronunciado en el mismo sentido varias veces (e igualmente las jurisdicciones superiores francesas).

Puede mencionarse asimismo el ejemplo sueco. Los suecos, lo mismo que los franceses, o los ingleses, u otros, pueden perfectamente considerar que existen casos en que la presencia de extranjeros de nacionalidad de los Estados Partes -este es el único ámbito de competencia del Comité Europeo de Derechos Sociales, ya que los nacionales de países terceros no le conciernen a priori- que se encuentren en su territorio plantean problemas de orden público, y que consiguientemente pueden desear expulsarles, en su caso de manera urgente, mediante una decisión administrativa previa; en cambio, no pueden expulsarles basándose en el orden público, la amenaza terrorista o el narcotráfico, sin que haya, al menos a posteriori, una vía de recurso disponible. Nos encontramos, a este respecto, en un marco jurídico, el del Consejo de Europa, que no es solamente el de la Carta, sino 
asimismo el del Convenio Europeo de Derechos Humanos, según el cual el Estado de Derecho se encuentra en el corazón de la democracia, según el cual toda decisión debe poder ser contestada ante un juez, siquiera sea a posteriori en los casos límite, pues de lo contrario entramos en el reino de la arbitrariedad.

\section{LA TAREA ESPECÍFICA DEL COMITÉ EUROPEO EN ÁMBITOS SOCIALES IMPORTANTES}

Más allá de las consideraciones generales efectuadas, tres temas merecen singularmente ser evocados por hallarse en el núcleo de las preocupaciones del Comité Europeo de Derechos Sociales: el empleo, la protección social, y la pobreza/la precariedad.

\section{El empleo}

Esta cuestión es tratada por el artículo 1, apartado 1, de la Carta, complementada por las disposiciones del artículo 10, apartados 3 y 4 sobre la formación de los adultos y por las disposiciones del artículo 15 relativo a las personas con discapacidad, y todos esos artículos a su vez combinados con el artículo $E$ sobre la no discriminación. En lo que concierne al empleo, la primera preocupación del Comité Europeo de Derechos Sociales consiste en velar por que los Estados desplieguen sus esfuerzos para asegurar el pleno empleo. Y, para apreciar la efectividad, la eficacia de tales esfuerzos, el Comité ha optado por acudir a una serie de indicadores que perfilan a la vez la situación económica nacional, los esfuerzos en materia de empleo y, a favor de la formación, la capacidad de las acciones formativas tendentes a buscar un puesto de trabajo a los parados de más o menos larga duración.

Pero la segunda preocupación del Comité Europeo de Derechos Sociales radica, por supuesto, en la lucha contra la discriminación, lo que implica no sólo que se declaren no conformes a la Carta las disposiciones jurídicas o las prácticas, o ambas, que perjudiquen a determinadas categorías de trabajadores, trabajadores a tiempo parcial especialmente, o a las mujeres (a menudo ambas condiciones coinciden). Por disposiciones jurídicas o prácticas que perjudiquen a determinadas categorías no debe entenderse únicamente aquellas que niegan a dichas categorías ventajas reconocidas a otras; debe entenderse asimismo aquellas otras que desconocen la exigencia de promover respuestas adaptadas a favor de grupos que se encuentren en situación particular. El Comité Europeo de Derechos Sociales en este ámbito se 
inscribe, como ha puesto de manifiesto en su decisión Autismo Europa contra Francia, en la misma línea que el Tribunal Europeo de Derechos Humanos en su sentencia Thilmmenos contra Grecia de 6 de abril de 2000, de modo que considera que, para que haya un tratamiento igual, no sólo debe tratarse idénticamente a personas que se encuentren en situaciones idénticas, sino asimismo no tratar idénticamente a personas que se encuentren en situaciones diferentes, mediando en caso contrario un incumplimiento de la obligación de trato igual.

Las relaciones laborales constituyen un ámbito bastante complicado, dado que las reglas y las prácticas son muy divergentes en los diferentes países ${ }^{10}$. El Comité Europeo de Derechos Sociales se esfuerza en este terreno en desarrollar análisis que permitan al mismo tiempo respetar las tradiciones nacionales y definir contornos comunes, y ello tanto en lo que afecta al derecho de sindicación como al derecho de huelga, o tanto en materia de derecho a la negociación colectiva como de derecho a la solución de conflictos laborales. Los debates sobre todas estas cuestiones son a menudo vivos en el propio seno del Comité. Así, el sistema austriaco (según el cual las negociaciones colectivas se sustentan en un diálogo entre organizaciones de adhesión obligatoria que son las únicas que ostentan el derecho de negociación colectiva sin autorización previa, mientras que la posibilidad de acceder a la negociación colectiva sólo queda abierta a las organizaciones de adhesión no obligatoria a condición de que cuenten con una autorización) obligó al Comité Europeo de Derechos Sociales a cuestionarse sobre las posibles peculiaridades por una parte y los límites infranqueables por otra. Del mismo modo, la cuestión de la solución por medio de ley de algunos conflictos colectivos (esencialmente en los países escandinavos), mientras que la solución de conflictos colectivos debería incumbir lógicamente sólo a los interlocutores sociales, o al juez, y por supuesto no bajo cualesquiera condiciones, dejó al Comité Europeo de Derechos Sociales en un cierto grado de perplejidad.

\section{La protección social}

La protección social constituye el objeto, directa o indirectamente, de varios artículos de la Carta: el artículo 12 - seguridad social-, el artículo 13 -asistencia social-, el artículo 15 -personas con discapacidad-, el artículo 16 -familia-, el artículo 17 -niños y adolescen-

10 Véase Belorgey, J. M.: «Gestion des conflits du travail en Europe: le choc des cultures", Droit Social, n. ${ }^{\circ}$ 12, diciembre 2002. 
tes-, y el artículo 23 -personas mayores-. En este terreno, una vez más, la diversidad de los modelos nacionales debe ser respetada. No se trata de armonizar, pues no es éste el papel que ha sido confiado al Comité de Derechos Sociales, ni es el objeto de la Carta. Hay sistemas que cuentan con una base profesional, mientras que otros están vinculados con la residencia en el territorio. Hay sistemas que se financian con impuestos, mientras que otros son financiados a través de cotizaciones, o incluso otros mediante mecanismos mixtos. Hay sistemas que, para la distribución de las prestaciones, llevan a cabo tests de recursos, mientras otros no lo hacen, y algunos otros acuden a tal efecto a métodos mixtos y cada vez más complejos. No se trata en absoluto de alinear todo ello sobre la base de un modelo único.

Pero las distinciones que se efectúen, en ocasiones arbitrarias, no deben tampoco ser cultivadas con exceso o bajo el signo de la duplicidad. No existe una diferencia teológica entre sistemas financiados por medio de impuestos y sistemas financiados mediante cotizaciones giradas sobre las rentas del trabajo. La preocupación del Comité Europeo de Derechos Sociales consiste en que todo ello funcione correcta y lealmente, sin que demasiadas personas queden al margen o los no nacionales sean sistemáticamente penalizados bajo pretextos falaces ${ }^{11}, y$ que el nivel de las prestaciones ofrecidas permita cubrir las necesidades en la medida en que los recursos del país lo hagan posible. $Y$ en esta sede nos enfrentamos con problemas complejos que tienen que ver con la relación entre la Carta y el Código Europeo de Seguridad Social; este último es un instrumento muy interesante, pero algunas de sus disposiciones han quedado un tanto desfasadas, particularmente la definición de familia; y algunas otras de sus disposiciones, si se las considera intangibles, van directamente contra la Carta. No se puede pretender a la vez un trato igual de los nacionales de los Estados miembros, con independencia de cualquier reciprocidad (la Carta es un instrumento multilateral), sin hablar de la aplicación del artículo E sobre la no discriminación (o el igual trato de los nacionales de los Estados

11 Como es el caso frecuente en materia de prestaciones de Seguridad Social, consideradas como no exportables desde el momento en que cada sistema nacional se basa en los impuestos o en la residencia; pero los trabajadores migrantes también pagan sus impuestos, lo mismo que las cotizaciones sociales; aceptar semejante razonamiento, cuando coexisten entre los países que han suscrito la Carta países que han organizado su sistema sobre bases diferentes, conduciría a que algunos trabajadores migrantes quedarían desprovistos de protección; y puesto que la Carta es un instrumento multilateral, ello comportaría asimismo tergiversar el alcance de la Carta, subordinando la resolución de los problemas correspondientes a la suscripción de acuerdos bilaterales. 
miembros - con algunas reservas-, que constituye el objeto mismo de la Carta), y considerar que no hay materias susceptibles de ser enriquecidas o que no debe actualizarse lo establecido en el Código de Seguridad Social.

Anteriormente se ha indicado que el nivel de prosperidad de los diferentes Estados Partes no dejaba indiferente al Comité. En materia de protección social, es evidente que hay países en donde conceder subsidios para los no activos, desempleados, personas mayores y discapacitados, que no estén exageradamente desfasados con respecto a las rentas de actividad y que no se sitúen por debajo del umbral de pobreza, es decir grosso modo por debajo de la mitad del salario medio, constituye un objetivo inalcanzable; en tal caso, es mejor que los países considerados no suscriban las obligaciones correspondientes, o que se les deje tiempo para poder satisfacerlas. Es obvio igualmente que el indicador que se ha dado el Comité Europeo de Derechos Sociales (no como un indicador absoluto, si bien debía hallarse un elemento de referencia para aplicar el mismo criterio a todos los países), la mitad del salario medio, asimilado al umbral de pobreza, no significa lo mismo en los diferentes países (sin duda, hay países para los cuales esto ni siquiera quiere decir gran cosa). Por último, debe tenerse presente la situación de los países en los que se han abierto camino grandes medidas de austeridad, como es el caso de los Países Bajos en materia de seguro de enfermedad. La cuestión que se plantea entonces es saber si las opciones operadas son o no compatibles con la Carta, y particularmente con las disposiciones de ésta que prohíben retroceder en los avances realizados ${ }^{12}$.

12 El artículo 12 de la Carta Social dispone que «Para garantizar el ejercicio efectivo del derecho a la seguridad social, las Partes se comprometen: 1. a establecer o mantener un régimen de seguridad social; 2 . a mantener el régimen de seguridad social en un nivel satisfactorio, equivalente, por lo menos, al exigido para la ratificación del Código Europeo de Seguridad Social; 3. a esforzarse por elevar progresivamente el nivel del régimen de seguridad social; (...)"; por su lado, el artículo $\mathrm{G}$ de la Carta revisada (anterior artículo 31 en la Carta de 1961), bajo la rúbrica "restricciones", establece que "1. Ios derechos y principios enunciados en la Parte I, una vez llevados a la práctica, así como su ejercicio efectivo con arreglo a lo dispuesto en la Parte II, no podrán ser objeto de restricciones o limitaciones que no estén especificadas en las Partes I y II, salvo las establecidas por la ley y que sean necesarias en una sociedad democrática para garantizar el respeto de los derechos y libertades de terceros o para proteger el orden público, la seguridad nacional, la salud pública o las buenas costumbres. 2. Las restricciones permitidas en virtud de la presente Carta a los derechos y obligaciones reconocidos en ella no podrán ser aplicadas con una finalidad distinta de aquélla para la que han sido previstas". Esta distinción ha sido interpretada como una cláusula de "stand still». 


\section{LA POBREZA Y LA PRECARIEDAD}

Lo que ha dicho en este terreno el Comité Europeo de Derechos Sociales no presenta una gran originalidad, puesto que en este frente sólo se han dado los primeros pasos. A tal efecto, ha indicado que la política contra la pobreza y la precariedad debe ser una política pujante y de progreso, y no sólo una política de reparación una vez ha sobrevenido la pobreza; que hay que prevenir la degradación de las situaciones que aboquen un día a la exclusión; que es preciso trabajar simultáneamente en los frentes del empleo, de la educación, de la protección social, de la vivienda y, utilizando una jerga que se está imponiendo en algunos otros foros, especialmente en el Consejo de Europa, que la política de lucha contra la pobreza y la precariedad debe ser una política de "mainstreaming", como la política de lucha contra las discriminaciones respecto de las mujeres. Dicho de otro modo, cuando se adopte una medida que a priori no interese en absoluto a los pobres, sino que haya sido puesta en marcha por ejemplo para conseguir el dinero que los servicios del fisco pretenden ingresar en las arcas públicas, o para simplificar algunos procedimientos, debe velarse por que el peso de ello no recaiga sobre los más pobres. Ciertamente, no es sencillo acometer este aspecto de la cuestión; para hacerlo, sería necesario que el Comité Europeo de Derechos Sociales estuviera dotado de una ciencia infusa, pues los países que presentan sus informes ante él no lo hacen nunca bajo el ángulo del "mainstreaming", debiendo entonces el Comité ir a la búsqueda de este enfoque para compensar el silencio de aquéllos. Se entenderá entonces por qué se ha cuestionado a Francia, por ejemplo, si lo que ha hecho en materia de recaudación de la tasa de televisión y que ha sido denunciado como perjudicial para los más pobres sin resolver ciertos problemas fiscales, no era sino contraproducente en materia de lucha contra la pobreza.

El «mainstreaming» es tanto más difícil de aprehender cuanto que se trata de una noción extraña al enfoque de la mayor parte de los países, que tienen tendencia a hablar de pobreza/precariedad esencialmente en términos de medidas curativas. El Comité Europeo de Derechos Sociales intenta, sin embargo, dialogar con los países que remiten sus informes, los interroga para ponderar la naturaleza de sus esfuerzos, con objeto de conocer si han entendido correctamente que la lucha contra la pobreza se juega en términos de progreso y pujanza, que no se trata sólo de articular las diferentes dimensiones de la lucha contra "la pobreza que esta aquí o que llega", sino de evitar que surjan pobres por adoptar medidas contraproducentes para el progreso. Obviamente, la cuestión del acceso a los derechos sociales de cualquier naturaleza 
forma parte integrante del esfuerzo de lucha contra la pobreza, y lo que el Comité ha pretendido decir en virtud del artículo 30 debe leerse en conjunción con lo que ha declarado sobre el acceso a los derechos sociales en virtud de otros artículos. Una cuestión está clara en materia de pobreza tanto o más que en otros ámbitos: hay que saber cuál es la situación. Ahora bien, muchos países practican en este terreno, o en el terreno del mal trato de las minorías o de subgrupos de personas con discapacidad, una política del avestruz. Por tal razón, el Comité ha afirmado en varias decisiones sobre reclamaciones colectivas, lo mismo que en las conclusiones realizadas sobre los informes presentados por los Estados, que la exigencia de conocimiento estadístico se encuentra en el meollo del respeto de la Carta. No puede haber respeto de la Carta Social si se dice, como lo han hecho Grecia o Italia en relación con los Gitanos, "en fin, ya saben, no se sabe cuántos hay" o "es preferible no contarlos; contarlos sería señalarles con el dedo". Pues no, hay que contar. Dicha obligación es primordial. Y una vez se ha hecho el cómputo, hay que saber decir qué es lo que se está haciendo a favor de los que han sido contados. Por su lado, Francia también dijo en el asunto Autismo Europa contra Francia: "Los autistas no queremos contarlos, ya que no queremos discriminar entre diferentes categorías de personas con discapacidad». El mismo razonamiento tiende a ser utilizado por ese mismo país en lo atinente a la discriminación por razón de origen étnico, introduciendo en su apoyo argumentos jurídicos (constitucionales). Si dicha posición no es abandonada, cabe temer que ello dé lugar a una acción de infracción o incumplimiento por no aplicación de las directivas de 2000. En lo que afecta a los autistas, algunas autoridades francesas -el Tribunal de Cuentas especialmente- habían declarado, por lo demás, lo mismo que el Comité, con anterioridad a éste: "Escuchen, si los autistas tienen problemas diferentes a los de las demás personas con discapacidad y ustedes no quieren contarlos, no llegarán nunca a resolver dichos problemas».

\section{REFLEXIONES FINALES}

La notoriedad, todavía insuficiente pero afortunadamente en progreso, de la Carta Social del Consejo de Europa, conduce a un número creciente e incesante de demandantes ante los órganos judiciales nacionales a invocar sus disposiciones en apoyo de los recursos formulados contra medidas individuales, normas reglamentarias e incluso, siquiera sea por vía de excepción de inconvencionalidad, legislativas; de manera más rara contra la abstención de los poderes públicos. Los argumentos barajados son, salvo en rarísimas excepciones nacionales 
que pueden contarse con los dedos ${ }^{13}$, implícita o explícitamente descartados sobre la base de que las disposiciones de la Carta no habrían sido introducidas en el orden jurídico interno de los Estados afectados ${ }^{14}$ comportando efectos directos.

Esto es lo que, por su parte, el Consejo de Estado francés mantuvo en una primera ocasión en $1984^{15}$. Desde entonces, ha persistido en se-

13 Países Bajos: Tribunal Supremo, 30 de marzo de 1986, que reconoce un efecto directo al artículo 6.4 de la Carta relativo al derecho de huelga; Bélgica: Consejo de Estado, 22 de marzo de 1995, Henry (solución implícita) sobre el mismo artículo, pero en cambio se alcanzó una conclusión distinta para el artículo 24; Alemania: Tribunal Federal del Trabajo, 10 de junio de 1986, Entscheidungen des Bundesarbeits Gerichts (pero no se consideró que hubo violación); República Checa: Tribunal Supremo, 22 C, doc 14/2001, en el que se acudió al artículo 16 de la Carta en un asunto de desahucio de unos inquilinos; 21 C, doc 1803/2003, en el que acudió al artículo 1.2 de la Carta en un asunto de despido; España: Tribunal Constitucional, en numerosas ocasiones se acudió a la Carta en la STC 11/1981 a propósito del derecho de huelga, STC 23/1983 y STC 210/1994 a propósito del derecho de sindicación, STC 5/1982 a propósito del derecho a la negociación colectiva, STC 146/1986 a propósito del derecho a la seguridad social, y STC 145/1991 a propósito de discriminaciones por razón de sexo (véase JIMENA QUESADA, L., y otros: Escritos sobre Derecho europeo de los derechos sociales, Valencia, Tirant lo Blanch, 2004, pp. 121 y siguientes).

${ }_{14} \mathrm{~A}$ fin de cuentas, estamos hablando de un número limitado de Estados que han firmado y ratificado la Carta pues si, entre dichos Estados sólo veintidós entran en la categoría de Estados monistas frente a doce que son Estados dualistas (si acaso, con respecto a dos Estados cabe albergar algunas dudas), la mayor parte de los Estados dualistas han incorporado la Carta a un buen nivel a su ordenamiento interno a través de diversos mecanismos, con sólo dos excepciones a las que se puso fin en 1991 (Finlandia) y en 2001 (República Checa), y otros dos supuestos en los que la incorporación que debía haber sido operada no lo fue (Noruega) o sólo se efectuó a un nivel infralegislativo (Suecia). Todo esto muestra que los países escandinavos han renunciado a ser el modelo social que parecía percibirse en los años 60. Ver ScIotTI, C.: «Applicabilité de la Charte sociale européenne dans I'ordre juridique interne des États contractants", en Droits sociaux et droits comparés, Journées d'études, 19 octobre 2001 (dir. J. F. FLauss), Nemesis/Bruylant, Bruxelles, 2002. Cabría cuestionar, bien es cierto, la coherencia intelectual de la posición de las autoridades y los jueces alemanes los cuales, pese a que las autoridades alemanas hayan llevado a cabo un procedimiento de ratificación de la Carta que comporta la incorporación de los tratados al ordenamiento jurídico germano, se inclinan a mantener que la Carta, o su interpretación, sería contraria a la Constitución alemana, lo que no es concebible, pues la ratificación/incorporación anteriormente mencionada sólo ha podido producirse de conformidad con la Constitución alemana; si ese no hubiera sido el caso, hubiera sido necesario, bien renunciar a la ratificación, bien modificar el texto constitucional.

${ }^{15}$ Conseil d'État, 20 avril 1984, Ministre délégué chargé du budget c/ Melle Valton et autres. 
mejante línea. Así, si bien la solución dada por el Consejo de Estado francés, en una reciente decisión GISTI, a un recurso formulado contra un decreto sobre el régimen de asistencia médica a los extranjeros, es idéntica en todos sus puntos a la que con anterioridad había sido alcanzada por el Comité Europeo de Derechos Sociales en la reclamación colectiva de la FIDH sobre la misma cuestión, y desarrollando los mismos argumentos, prefirió en cambio fundarse en el artículo 3.1 de la Convención relativa a los derechos del niños de 26 de enero de 1990. La decisión controvertida se vio incluso en la necesidad de indicar lo siguiente: "En lo que concierne a los argumentos basados en el incumplimiento del Pacto internacional de derechos económicos, sociales y culturales, del Pacto internacional de derechos civiles y políticos, y de la Carta Social Europea revisada: considerando, de un lado, que en virtud de los artículos 9 y 10 del Pacto internacional de derechos económicos, sociales y culturales, los Estados Partes reconocen el derecho de toda persona a la seguridad social, incluyendo los seguros sociales, así como una protección y una asistencia tan amplia como sea posible a la familia; que, igualmente, según los artículos 11, 12, 13 y 17 de la Carta Social Europea revisada, las Partes se comprometen a adoptar medidas apropiadas para asegurar el ejercicio efectivo, respectivamente, del derecho a la protección de la salud, del derecho a la seguridad social, del derecho a la asistencia social y médica, y del derecho de los niños y adolescentes a crecer en un medio favorable para el pleno desarrollo de su personalidad y el desarrollo de sus aptitudes físicas y mentales; que dichas estipulaciones, que no surten efectos directos respecto de los particulares, no es dado invocarlas para sostener conclusiones tendentes a la anulación de los decretos impugnados; que de ello se desprende que el argumento basado en que los derechos enunciados por la Carta Social Europea revisada no quedarían garantizados en el respeto del principio de no discriminación previsto por el artículo E... de la Carta, es igualmente inoperante; ...".

El mismo ostracismo de la Carta Social no figura explícitamente en otra decisión reciente del Consejo de Estado, del pleno de la Sala contencioso-administrativa en este caso, dictada en otro recurso formulado por el GISTI en relación con el derecho de sufragio activo y pasivo de los extranjeros en las elecciones para las Cámaras de artes y oficios, pero el Comisario del Gobierno (Abogado del Estado) sí había retomado la argumentación controvertida.

El caso es que, como recordaba en 1979 el Presidente Laroque [del Comité Europeo de Derechos Sociales, entonces Comité de Expertos Independientes] en un artículo de Droit Social dedicado a la Carta Social: "... Entre los Estados... dos concepciones se oponen en lo relativo a la 
aplicación directa de las convenciones internacionales normativas en su ordenamiento interno. Para unos, la ratificación de la convención basta por sí misma para incorporarla al ordenamiento interno $y$, desde ese momento, los interesados pueden, tanto soportar los efectos de ella en su contra como hacerla valer a su favor. Las autoridades públicas, y los órganos judiciales de todos los órdenes, deben asegurar su aplicación. Para otros, la convención sólo puede ser introducida en el ordenamiento interno en virtud de disposiciones adoptadas especialmente a tal efecto por los poderes públicos nacionales; los interesados sólo pueden verse confrontados a esas últimas disposiciones de Derecho interno, y no en cambio directamente a la convención...".

Naturalmente, en cada Estado, cuando no existan en el texto mismo de los acuerdos internacionales o en las constituciones nacionales disposiciones explícitas a tal efecto, corresponderá a los jueces en última instancia decidir la concepción que prevalece. Cabe ponderar, de paso, la cautela con la que se acomete la menos avanzada, o la más restrictiva de estas concepciones, en las disposiciones del proyecto de Tratado constitucional europeo que prevén que los principios de la Carta de los derechos fundamentales de la Unión Europea pueden ser puestos en práctica mediante disposiciones legislativas y normas ejecutivas previstas por las instituciones y órganos de la Unión, y mediante actos de los Estados miembros cuando den cumplimiento al Derecho de la Unión, en el ejercicio de sus competencias respectivas; sin embargo, la invocación de dichos principios ante el juez sólo se admite para la interpretación y el control de legalidad de dichos actos (es posible hallar una formulación muy próxima, e igualmente frustrante, en la Constitución española, según la cual, tras haber reconocido un cierto número de derechos sociales, precisa que éstos sólo podrán ser invocados ante los órganos de la jurisdicción ordinaria de conformidad con las disposiciones que los desarrollen).

De todas las nociones cultivadas por los jueces en general, y los del orden contencioso-administrativo en particular, para justificar jurídicamente la distinción que se han acostumbrado a efectuar entre argumentos pertinentes y argumentos no pertinentes, la noción de efecto directo constituye sin lugar a dudas y con toda evidencia (es muy raro que surja la necesidad de cimentar o apuntalar dicha noción), una de las más ambiguas. Los argumentos barajados, tanto a partir del modo en que se enuncia en los diferentes textos aplicables como a partir de los usos jurisprudenciales, no son en la mayor parte de las veces sino el ropaje que se pone a las preferencias o al rechazo (con respecto al Derecho internacional o a algunas categorías de derechos, en particular los derechos sociales). 
La verdad es que, más allá de argucias jurídicas, dos razones explican la crispación de los jueces nacionales:

- La persistencia de reflejos de soberanía (soberanía nacional, soberanía de los tribunales denominados "soberanos", y que de hecho ya no lo son, desde el momento en que los veredictos de las jurisdicciones internacionales deben ser tomados en cuenta por las jurisdicciones nacionales, a menos que se vulneren los compromisos internacionales),

- La persistencia asimismo de una concepción desfasada de la naturaleza de los derechos sociales, que serían, en esencia, diferentes de los demás derechos, en la medida en que se trataría no tanto de derechos-libertad sino de derechos-crédito; en otras palabras, no se trataría exactamente de derechos, sino más bien de enunciados programáticos que impondrían, en el mejor de los casos, una obligación de concreción a un productor de normas interpuestas (legislador o poder reglamentario), sin que el destinatario final pueda, por su parte, hacer valer un derecho subjetivo ${ }^{16}$.

No es que semejante representación esté ya desfasada, sino que procede, siempre ha procedido, de una pura y simple cuestión de principio. Pues conviene observar que los derechos-libertad no pueden ellos mismos, la mayor parte de las veces, ser concretados más que a través de la intervención de los poderes, legislativo o reglamentario, intervención que comporta un coste; o pensemos también en que el derecho a la educación, al que en general se suele conferir un tratamiento más favorable que a los demás derechos sociales -derecho a la salud, derecho a la vivienda-, comporta gastos tan considerables como esos otros derechos ${ }^{17}$.

${ }^{16}$ Véase el trabajo del profesor en la Universidad de Tracia y en la Universidad Robert Schuman de Estrasburgo, así como miembro del Comité Europeo de Derechos Sociales, AlipRANTIS, N.: "Les droits sociaux sont justiciables", Droit Social, n. ${ }^{\circ} 2$, febrero 2006.

17 Las dos razones esgrimidas pueden evidentemente combinarse con una tercera más frustrante: la que se reconduce a la repugnancia que muestran algunos juristas o pensadores políticos de algunos países - sobre todo, de la Europa del Este- con relación a toda especie de normas, en particular las internacionales, que evoquen un "socialismo de Europa occidental». Es a esta repugnancia a la que se enfrentó, en la República Checa, antes de la reforma constitucional de 2001, la ratificación de la Carta Social Europea (ver ScıotTI, C.: op. cit.). Puede hallarse una formulación impactante y especialmente reivindicativa de esta forma de ver las cosas en MACIEJEWSKA, J.: "European Social Charter practice: legalism or common sense», en The polish quaterly of International affairs, Summer 2005, p. 45 y si- 
Por lo demás, es particularmente ilustrativo observar cómo, en el curso de los años, la actitud de los órganos jurisdiccionales nacionales revela, a la hora de manejar la noción de efecto directo (o de defecto de efecto directo) de los acuerdos internacionales adoptados en diferentes materias, entre ellas la materia social, inflexiones significativas. Así sucede en el caso del Convenio Europeo de Derechos Humanos, o de la Convención internacional de los derechos del niño.

Por consiguiente, es difícil llegar a convencerse de la racionalidad de la postura mantenida por el Consejo de Estado francés, incluso al acudir a las sabias conclusiones de Rony Abraham, en la sentencia GISTI de 23 de abril de 1997. Lo esencial del razonamiento seguido por este comisario del gobierno consiste en argüir:

- En un primer momento, con apoyo en la sentencia Kupferberg dictada en 1982 por el Tribunal Europeo de Derechos Humanos, que:

a) Los Estados Partes no tienen la obligación de introducir, en su ordenamiento jurídico nacional, un tratado que no ha previsto su aplicabilidad directa en Derecho interno;

b) Esto no significa que el tratado habría entendido que excluye su efecto directo en Derecho interno, sino únicamente que cada Estado es libre de adoptar a este respecto las reglas que prefiera;

- En un segundo momento:

a) Que, en Francia, a la vista del tenor del artículo 26 de la Constitución de 1946, confirmado por el artículo 55 de la Constitución francesa de 1958, los tratados internacionales incorporados al ordenamiento jurídico nacional por efecto de su

guientes, en donde se critica de manera sesgada las ignorancias que revelarían las conclusiones del Comité Europeo de Derechos Sociales sin realmente haber leído éstas. Pero no nos encontramos lejos de semejante postura insultantemente polémica si leemos el reciente artículo de RENUCCI, J. F. y BIRSAN, C.: "La Cour européenne des droits de l'homme et la Charte sociale européenne: des liens dangereux", Étude et commentaires, Notes, Recueil Dalloz, 2007, artículo que cultiva temas trampa, al situar a los Estados como «comprometidos más allá de sus compromisos», al hablar de la ausencia de valor vinculante de la Carta y del peligro que representa la utilización por el Tribunal Europeo de las referencias a la Cara, sobre todo cuando los artículos a los que se hace referencia no han sido aceptados por el Estado concernido. Sin embargo, no es nuevo el método de intentar clarificar el alcance de las disposiciones de un texto a través de las de otro texto, lo cual no implica que éste tenga un carácter aplicable. 
ratificación y de su publicación en el Diario Oficial, se presume que surten efectos directos en Derecho interno, es decir, que crean derechos subjetivos que los particulares pueden hacer valer ante el juez nacional;

b) Pero que esta presunción cede en dos hipótesis: la primera, cuando el propio objeto de la norma convencional consista en regular exclusivamente las relaciones entre los Estados Partes, y no en garantizar derechos en beneficio de los particulares; la segunda, cuando las estipulaciones internacionales que tengan por objeto garantizar derechos a los particulares estén formuladas en términos demasiado generales para ser autosuficientes.

No resulta indiferente observar que entre las hipótesis en las que el principio está llamado a ceder, el propio comisario del gobierno había rehusado hacer figurar una tercera, aquella según la cual algunas redacciones tales como "los Estados Partes se comprometen a garantizar" una ventaja, o "se comprometen a reconocer" un derecho (redacciones empleadas en el Pacto de Nacionales Unidas sobre derechos económicos, sociales y culturales, y en la Carta Social Europea) conducirían a la consecuencia, ellas mismas, de excluir el efecto directo, mientras que la expresión "los Estados reconocen" o "los Estados garantizan" los derechos enumerados no sólo no excluiría ese efecto directo, sino que incluso lo implicaría... "Permítasenos -indicaba aquél- expresar a este respecto el más grande escepticismo. La redacción utilizada no es ciertamente indiferente. En nuestra opinión, es un índice que puede jugar en apoyo de una de las dos grandes causas de ausencia de efecto directo: de un lado, la fórmula "los Estados se comprometen a asegurar", confirma que el objeto de la regla que sigue es organizar las relaciones entre Estados; de otro lado, confirma asimismo la idea de que la norma internacional opera necesariamente una llamada a una legislación interna de aplicación. Pero tenemos verdaderas dificultades para ver en ello un criterio autónomo, suficiente, sobre la ausencia de efecto directo. Por una parte, porque existe una infinidad de matices en las fórmulas empleadas por las convenciones internacionales, pese a que el criterio de la redacción sea de un manejo más que delicado; por otra parte, porque con ello se atribuye a la común intención de las Partes mucho más de lo que se les puede razonablemente atribuir al ver en el empleo de tal o cual fórmula la prueba de que los redactores habrían pretendido descartar el efecto directo: como ya hemos tenido ocasión de decirlo, a los autores de un tratado les es generalmente indiferente su estatuto en el ordenamiento interno, 
y dejan esta cuestión para el Derecho nacional, especialmente en el caso de grandes convenciones multilaterales a las que se adhieren a la vez Estados "monistas" y Estados "dualistas"...".

El caso es que la Carta Social Europea puede, se convendrá en ello, ser considerada desde diversos puntos de vista como más compleja que los demás instrumentos internacionales. El Presidente Laroque, por su parte, en el artículo anteriormente citado, razonaba de modo absolutamente claro que "... de un lado, el propio texto de los artículos de la parte II de la Carta está redactado de tal forma que prevé el compromiso de las Partes Contratantes de tomar ciertas medidas, salvo en algunos raros apartados en donde las Partes Contratantes declaran "reconocer" algunos derechos, limitándose en general a comprometerse a hacer algo; de otro lado, el anexo a la Carta estipula expresamente que se entiende que la Carta contiene compromisos jurídicos de carácter internacional cuya aplicación queda sometida únicamente al control previsto por la Parte IV. Esta fórmula, a primera vista un tanto oscura, queda aclarada por los trabajos preparatorios. Se introdujo precisamente para excluir cualquier posibilidad de que los individuos pudieran hacer valer directamente ante las autoridades o las jurisdicciones nacionales las disposiciones de la Carta. De ello se desprende que los compromisos suscritos por las Partes Contratantes son únicamente compromisos de Estado a Estado, cuyas únicas sanciones, de carácter internacional, son las previstas en la parte IV॥.

Sin embargo, las cosas no parecen ser tan sencillas. El análisis que precede, por añadidura, fue escrito hace ya más de un cuarto de siglo. $Y$ ha hecho falta menos tiempo para que jurisprudencias que reflejaban en otros frentes, pero en la misma época, el mismo estado de opinión, experimenten un giro radical ${ }^{18}$.

Ya de entrada, el esquema general de redacción de la Carta, por más que pueda encerrar virtudes pedagógicas, da pie seguramente a tentativas de interpretación a la baja. Únicamente la parte I de la Carta enumera derechos; los de "todo trabajadon", de "todo trabajador migrante", y más raramente (y ello no significa, como se indicó anteriormente, la misma cosa que en el Convenio Europeo de Derechos Humanos) de "toda persona". Los artículos comprendidos en la parte II no describen por su lado a qué "las Partes se comprometen". Ello no obstante, un vínculo se establece explícitamente entre la parte I y la parte II mediante la fórmula que figura encabezando cada artículo de la parte II,

18 Véase BELORGEY, J. M.: "Gouvernance internationale: la contribution des juges", Revue politique et parlementaire, 2006. 
precediendo a la referencia sobre el compromiso de las Partes: "Para garantizar el ejercicio efectivo del derecho a...". Sin duda, aquello sobre lo que versan los compromisos de los Estados no reviste, a mayor abundamiento, el mismo alcance en todos los artículos. Pero ese es otro debate. Qué sentido tiene reconocer derechos si tales derechos están desprovistos de sustancia; y qué puede querer decir la afirmación del artículo 4 de la Carta, según la cual "todos los trabajadores tienen derecho a una remuneración suficiente que les proporcione a ellos y a sus familias un nivel de vida decoroso", si no es para, por una parte, entender que dicha remuneración debe estar en relación con el coste de la vida y, por otra parte, que esa remuneración no puede dejar de ser abonada sin preaviso razonable; en otro caso, podría prescindirse de la parte II.

En cuanto al alcance conferido por el Presidente Laroque a la disposición del anexo según la cual "se entiende que la Carta contiene compromisos jurídicos de carácter internacional cuya aplicación queda sometida únicamente al control previsto por la Parte IV» (en sus orígenes, informes de los Estados, mientras en la actualidad informes de los Estados y reclamaciones colectivas), es preciso:

- En primer lugar, plantear si esas intenciones no quedan desmentidas por la letra del texto adoptado, puesto que prever como lo hace el anexo de la Carta que "se entiende que la Carta contiene compromisos jurídicos de carácter internacional cuya aplicación queda sometida únicamente al control previsto por la Parte IV» (el del Comité Europeo de Derechos Sociales), no significa evidentemente que las jurisdicciones internacionales no tengan vocación de aplicar la Carta, y de atribuirle efectos directos, sino únicamente que en el plano internacional es sólo el Comité Europeo de Derechos Sociales quien tiene dicha vocación;

- En segundo lugar, explicar por qué los signatarios de la Carta rechazaron vincularse por una proposición tendente a establecer que "las disposiciones de la Carta no confieren derechos directos a los individuos, etc...", si eran favorables a dicha tesis, pues semejante formulación habría puesto fin seguramente a cualquier debate,

- Por último, aun suponiendo que la tesis de la ausencia de efectos directos se corresponda con las intenciones originarias de algunas Partes signatarias de la Carta, incluso de todas, plantear seriamente la cuestión acerca de si esa postura es en la actualidad compatible con la evolución del pensamiento en la materia, si no desde el Derecho social, al menos sí en materia de Derecho internacional: un Derecho internacional que no sea puramente decorativo. 


\section{Title}

The European Social Charter of the Council of Europe and its control mechanism: the European Committee of Social Rights

\section{Summary}

I. Introductory remarks: focus on the European Social Charter. II. Characterization and scope of the power of the European Committee of Social Rights. III. Contribution of the European Committee to the progress of social rights. IV. The specific task of the European Committee in important social areas: 1 . The employment. 2 . The social protection. 3. The poverty and the social exclusion. V. Concluding thoughts.

\section{Resumen}

Este trabajo presenta la Carta Social Europea como el tratado internacional más importante en materia de derechos sociales, no sólo desde el punto de vista del número de derechos reconocidos, sino sobre todo desde la perspectiva de la protección efectiva de tales derechos. Precisamente, el Comité Europeo de Derechos Sociales ha contribuido decisivamente con su jurisprudencia a reforzar el mecanismo de control de la Carta Social, primero mediante el sistema de informes y después asimismo a través del sistema de reclamaciones colectivas. El Comité Europeo ha permitido confirmar que la Carta Social es un tratado que establece verdaderas obligaciones internacionales, y no meras declaraciones programáticas. En este sentido, la jurisprudencia del Comité Europeo de Derechos Sociales ha conocido un desarrollo significativo en materia de empleo, de protección social y de lucha contra pobreza y la exclusión social. En todo caso, el Comité Europeo respeta las tradiciones y la diversidad de los Estados Partes en la Carta Social, forjando al mismo tiempo una especie de constitucionalismo social europeo. De este modo, el Comité diseña un estándar común en materia de protección efectiva de derechos sociales que relativiza la cuestión de la incorporación de la Carta Social y su aplicabilidad directa en los ordenamientos internos.

\section{Abstract}

This essay presents the European Social Charter as the most important international treaty in the field social rights, not only from the point of view of the number of recognized rights, but especially from 
the perspective of the effective protection of such rights. Precisely, the European Committee of Social Rights has contributed with its case law to enhance decisively the mechanism of control, both by means of the reporting system of reports and by means of the collective claims system. The European Committee has confirmed that the Social Charter is a treaty that establishes real international obligations, and not mere programmatical declarations (soft law).

In this respect, the case law front the European Committee of Social Rights has known a significant development as for employment, social protection and fight against poverty and social exclusion. In any case, the European Committee respects the traditions and the diversity of the States Parties to the Social Charter, forging at the same time a kind of social European constitutionalism. Thus, the Committee builds a common standard as for effective protection of social rights that relativizes the issue of the incorporation of the Social Charter and its direct applicability in the national legal orders.

\section{Palabras clave}

Actividad jurisdiccional o cuasi jurisdiccional, jurisdicción internacional, progreso de los derechos sociales, reclamaciones colectivas, prevención de conflictos individuales, competencias de los interlocutores sociales y de las entidades locales, responsabilidad del Estado, buenos textos y buenos prácticas, diversidad de modelos nacionales, estándar común, justiciabilidad, uso de la Carta Social en el ámbito interno, aplicabilidad directa.

\section{Key words}

Jurisdictional or cuasi jurisdictional activity, international jurisdiction, progress of social rights, collective claims, prevention of individual conflicts, competences of social agents and of local authorities, responsibility of the State, good texts and good practices, diversity of national models, common standard, justiciability, use of the Social Charter at domestic level, direct applicability. 